\title{
RARE BUT THERE: MALE BREAST CANCER
}

Raj. Nagarkar ${ }^{1}$, Sirshendu Roy², Aditya Adhav³, Abhishek Jadhav 4 , Ashutosh Tondare 5

${ }^{1}$ Consultant, Department of Surgical Oncology, Curie Manavata Cancer Centre.

${ }^{2}$ Consultant, Department of Surgical Oncology, Curie Manavata Cancer Centre.

${ }^{3}$ Fellow, Department of Surgical Oncology, Curie Manavata Cancer Centre.

${ }^{4}$ Fellow, Department of Surgical Oncology, Curie Manavata Cancer Centre.

${ }^{5}$ Consultant, Department of Surgical Oncology, Curie Manavata Cancer Centre.

\section{ABSTRACT}

Male Breast Cancer (MBC) is a rare disease representing less than $1 \%$ of all malignancies in men and only $1 \%$ of all incident breast cancers. Our study details incidence of male breast carcinoma at a Tertiary Cancer Centre. Thirteen patients were collected from 2007 to 2015 at the Curie Manavata Cancer Centre, Nashik. The main complaint was a mass beneath the areola. All were ductal carcinomas. Management consisted of radical mastectomy; radiotherapy and hormonal therapy with or without chemotherapy. Two patients presented with metastasis, the site of metastasis was lung. Male breast cancer has many similarities to breast cancer in women, but there are distinct features that should be appreciated. Future research for better understanding of this disease at various levels is needed to improve the management and prognosis of male patients.

\section{KEYWORDS}

Male Breast Cancer.

HOW TO CITE THIS ARTICLE: Raj. Nagarkar, Sirshendu Roy, Aditya Adhav, Abhishek Jadhav, Ashutosh Tondare. "Rare But There: Male Breast Cancer." Journal of Evolution of Medical and Dental Sciences 2015; Vol. 4, Issue 100, December 14; Page: 16551-16553, DOI: $10.14260 /$ jemds/2015/2463

\section{INTRODUCTION}

Female breast received maximum attention. Male breast is ignored due to its rudimentary and non-functional nature. Problems of male breast are carcinoma, gynecomastia, lipoma, sarcoma and metastasis. The epidemiology of male breast carcinoma is not known. Male breast cancer is a rare disease that accounts for less than $1 \%$ of all cancers in men and less than $1 \%$ of all diagnosed breast cancers. ${ }^{1}$ Risk factors being less awareness leading to cases presenting late, which in turn leads to local infiltration and distant metastasis.

\section{AIM}

The incidence of male breast carcinoma at a Tertiary Cancer Centre.

\section{MATERIALS AND METHODS}

All male patients with lump in the breast attending OPD were included. Staging was carried out according to the TNM classification. Diagnosis was made by biopsy of the breast tumor. Based on the diagnosis, patients underwent modified radical mastectomy with axillary clearance and immunohistochemical analysis to determine Estrogen (ER) and Progesterone Receptor (PR) and HER2 status. It was a retrospective study of 8 years duration (May 2007 to October 2015). Total no. of patients 13 .

\section{RESULTS}

In the present study, 13 patients with age ranging from 45-75 yrs with carcinoma breast were evaluated. The age wise incidence ranged from 45 to 75 years (Figure 1).

Financial or Other, Competing Interest: None.

Submission 06-11-2015, Peer Review 07-11-2015,

Acceptance 05-12-2015, Published 14-12-2015.

Corresponding Author:

Dr. Aditya Adhav,

Adhav Hospital, Shivajinagar,

Opp. Inox Theatre,

Nashik-422006.

E-mail: adityaadhav25@gmail.com

DOI:10.14260/jemds/2015/2463

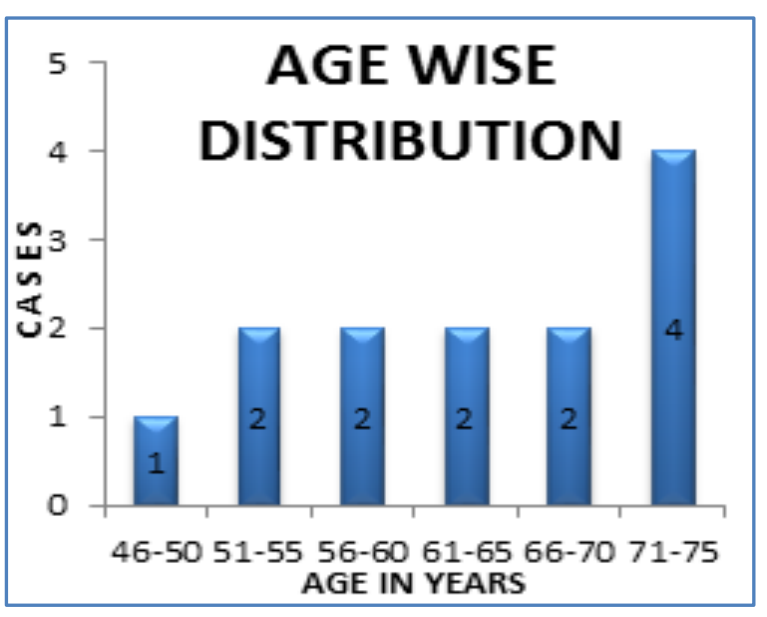

Fig.1: Age wise incidence of male breast carcinoma

Maximum number $4(31 \%)$ of patients were found in the age group of 71-75 years. All the 13 patients presented with chief complaints of lump in the breast; $7 / 13(54 \%)$ had lump in right breast and 6/13(46\%) in left breast (Figure 2).

\section{SIDE OF THE LUMP}

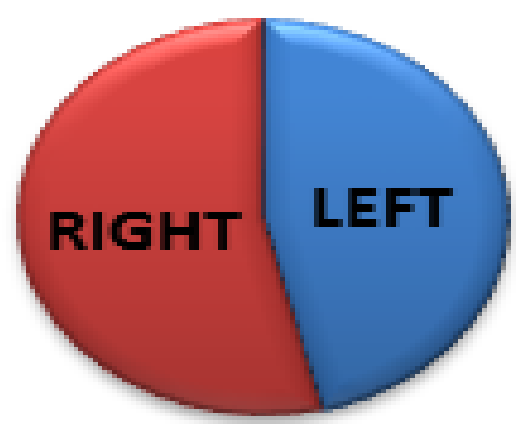

Fig. 2: Sides involved 
According to the TNM classification, tumors were categorized as T1: 3 cases (23\%), T2: 4 cases (31\%) and T4: 6 cases (46\%). Tumors were classed as N1 and N2 respectively, in $4(31 \%)$ and $1(8 \%)$ of the cases; $2(15 \%)$ patients initially had lung metastases (Figure 3).

\section{METASTASIS}

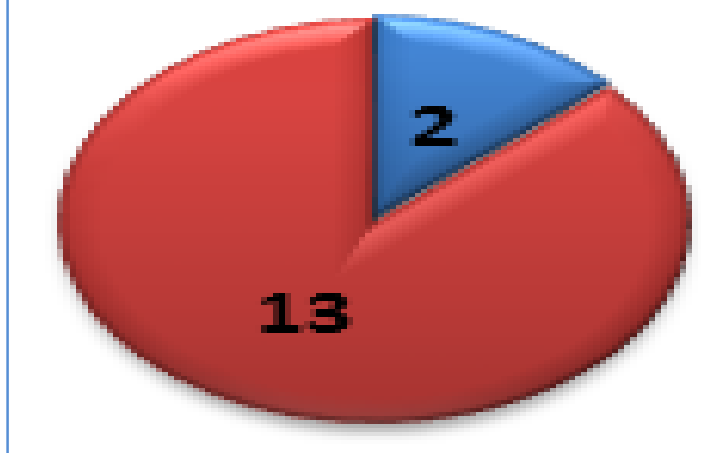

Fig.3: Metastatic and Non-metastatic

Histological reports proved all (100\%) to be intraductal carcinoma. Of the 13 patients, $9(69 \%)$ patients were subjected to modified radical mastectomy, $6(46 \%)$ patients received adjuvant chemotherapy of the $6,3(50 \%)$ received CEF, $2(33 \%)$ received CAF with Paclitaxel and 1(17\%) received paclitaxel with trastuzumab, 3(23\%) received adjuvant radiation and $8(62 \%)$ received adjuvant hormonal therapy with tamoxifen (Figure 4).

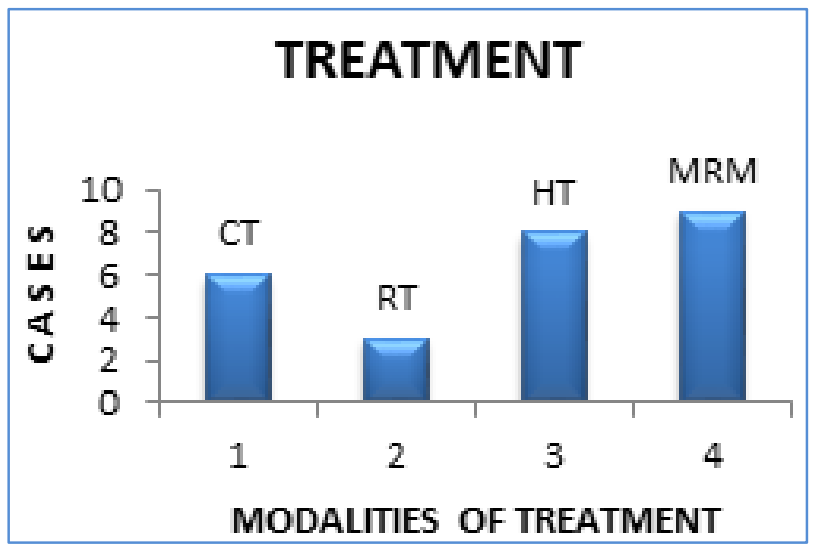

Fig. 4: Modalities of Treatment

\section{DISCUSSION}

Male breast cancer has many similarities with breast cancer in women, but there are distinct features that should be appreciated. During the last few years, there has been an increase in the incidence of this disease. Review of Surveillance, Epidemiology and End Result (SEER) data stated a rise in the incidence of male breast cancer from 1.0 per 100,000 men in 1970 s to $<1.3$ per 100,000 men between 2000 to 2004.1,2 The mean age at diagnosis for men with breast cancer is 65-70 years, which is approximately 5-10 years older than the average age at diagnosis for women. ${ }^{1,3}$ The age group in our patients (71-75 years) is higher than other series. Male breast cancer is likely to be caused by the convergent effects of different risk factors like hormonal imbalances, occupation, environment and genetic risk factors like family history of breast cancer and BRCA mutations. ${ }^{3}$ The most common clinical sign of breast cancer onset in men is a painless palpable retroareolar lump. ${ }^{4}$ Other symptoms might be nipple involvement with retraction and/or ulceration and/or bleeding, axillary lymphoadenopathies and gynecomastia.3,4 As lobular elements are absent in male breast, Invasive Ductal Carcinoma (IDC) is the most frequently encountered male breast cancer type (85-95\%).4,5

The result in our study was similar with a $100 \%$ for IDC and this was significantly higher than the other histological types. Lobular carcinoma in situ, Paget disease and inflammatory breast cancer have been rarely described in men. ${ }^{5}$ Positivity rate of receptors is more frequent in men with breast cancer in comparison to women. ${ }^{6}$ In different studies, ER and PR positivity was reported as $75 \%$ to $93 \%{ }^{7,8}$ In our study, both Estrogen Receptor (ER) and Progesterone Receptor (PR) were positive in $62 \%$. Breast cancer in men should be treated with the same strategy as in women.9,10 The surgical procedure of choice is modified radical mastectomy with axillary node dissection. ${ }^{11}$ Recent literature is in favor of modified radical or simple mastectomy combined with radiation therapy.

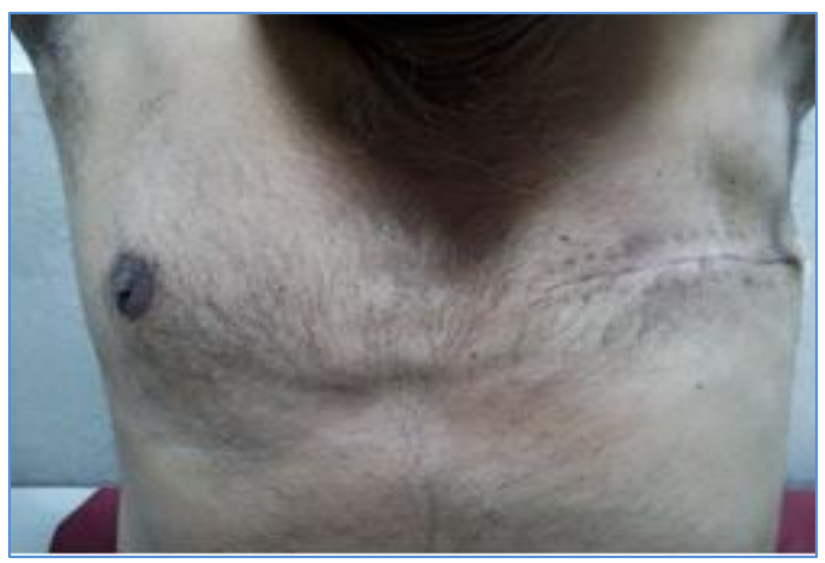

Postoperative radiotherapy achieves local control, but no effect is observed on survival. ${ }^{12}$ In men treated with mastectomy, adjuvant radiotherapy has shown to decrease local recurrence. ${ }^{13}$ Tamoxifen is proven to increase survival rates in women with hormone-responsive disease and till date is considered the standard adjuvant treatment for hormonedependent male breast cancer. ${ }^{14}$ The drug tolerance has not been sufficiently studied in men. Its main side effects are deep venous thrombosis, reduction of libido, impotence, mood changes and hot flushes. ${ }^{15}$

Chemotherapy is to be used in the absence or doubt about endocrine-responsiveness. Frequently used chemotherapy regimens were CMF, FEC and EC.16 In lymph node positive disease, taxanes should be used. Adjuvant trastuzumab therapy, no specific data exists, it is used according to patient's and tumor characteristics. ${ }^{17,18}$ The overall 5- and 10-year survival rate of male breast cancer patients are around $60 \%$ and $40 \%$ respectively. ${ }^{17}$ The tumour size and number of histologically positive axillary nodes and there are significant prognostic factors. Advanced age at the time of diagnosis is another negative prognostic factor as presence of comorbidities may limit the possibility of treatment. 18

\section{CONCLUSION}

Lifetime risk in women with breast cancer is better than in men. While some investigators explain this with more aggressive biologic behaviour of male breast cancer, more frequent explanation is the rarity of male breast cancer and its diagnosis at a more advanced stage. Future research for better understanding of this disease at various levels is needed to improve the management and prognosis of male patients. 


\section{REFERENCES}

1. Cutuli B, Cohen-Solal Le-Nir C, Serin D, Kirova Y, Gaci Z, Lemanski C, Male breast cancer, et al.: Evolution of treatment and prognostic factors. Analysis of 489 cases. Critical Reviews in Oncology/Hematology 2010;73:246-254.

2. Speirs V, Shaaban AM: The rising incidence of male breast cancer. Breast Cancer Res Treat 2009;115:429-430.

3. Yoney A, Kucuk A, Unsal M, et al.: Male breast cancer: A retrospective analysis. Cancer/Radiothérapie 2009;13:103-107. PubMed Abstract.

4. Fiala L, Coufal O, Fait V, et al.: Male breast cancer: our experience. Rozhl Chir 2010;89(10):612-8. PubMed Abstract.

5. Ben Dhiab T, Bouzid T, Gamoudi A, Ben Hassouna J, Khomsi F, Boussen H, et al.: Male breast cancer: about 123 cases collected at the Institute Salah-Azaiz of Tunis from 1979 to 1999. Bull Cancer 2005;92(3):281-5. PubMed Abstract Publisher Full Text.

6. El Omari-Alaoui H, Lahdiri I, Nejjar I, Hadadi K, Ahyoud $\mathrm{F}$, Hachi $\mathrm{H}$, Male breast cancer, et al.: A report of 71 cases. Cancer/Radiotherapie 2002;(6):349-351.

7. Yoney A, Kucuk A, Unsal M: Male breast cancer: a retrospective analysis. Cancer/Radiothérapie 2009;13:103-7. PubMed Abstract.

8. Comet B, Cutuli B, Penault-Llorca F, et al.: Male breast cancer: a review. Bull Cancer 2009;96(2):181-9. PubMed Abstract Publisher Full Text.

9. Contractor KB, Kaur K, Rodrigues GS, et al.: Male breast cancer: is the scenario changing? World J Surg Oncol 2008;6:58-69. PubMed Abstract BioMed Central Full Text PubMed Central Full Text.

10. NCCN (National Comprehensive Cancer Network) Breast Cancer Guidelines [http://www.nccn.org] webcite
11. Onami Susan, Ozaki Melanie, Mortimer Joanne E, et al.: Male breast cancer: An update in diagnosis, treatment and molecular profiling. Maturitas 65(2010):308-314.

12. Yu E, Suzuki H, Younus J, Elfiki T, Stitt L, Yau G, et al.: The Impact of post-mastectomy radiation therapy on male breast cancer patients-A case series. Int J Radiat Oncol Biol Phys 2012 Feb 1;82(2):696-700.

13. Pant $\mathrm{K}$, Dutta $\mathrm{U}$, et al.: Understanding and management of male breast cancer: a critical review. Med Oncol 2008;25(3):294-8. PubMed Abstract Publisher Full Text.

14. Fogh S, Hirsch AE, Langmead JP, Goldberg SI, Rosenberg CL, Taghian AG, et al.: Use of tamoxifen with postsurgical irradiation may improve survival in estrogen and progesterone receptor-positive male breast cancer. Clin Breast Cancer 2011;11(1):39-45. PubMed Abstract Publisher Full Text.

15. Arnould N, Pouget $\mathrm{O}$, Gharbi M, et al.: Breast cancer in men: are there similarities with breast cancer in women? Gynécologie Obstétrique \& Fertilité 2006;34:413-419. PubMed Abstract.

16. Tunon de Lara C, Goudy G, MacGrogan G, Durand M, Dilhuydy J-M, Avril A, et al.: Male breast cancer: A review of 52 cases collected at the Institute Bergonie (Bordeaux, France) from 1980 to 2004. Gynécologie Obstétrique and Fertilité 2008;36:386-394. PubMed Abstract.

17. Gómez-Raposo C, Zambrana Tévar F, Sereno Moyano M, et al.: Male breast cancer. Cancer Treatment Reviews 2010, in press.

18. Ottini Laura, Palli Domenico, Rizzo Sergio, Federico Mario, Bazan Viviana, Antonio Russo, et al.: Male breast cancer. Critical Reviews in Oncology/Hematology 2010;73:141-155. PubMed Abstract Publisher Full Text. 